\title{
EXPERIMENTAL STUDY ON CORROSION MONITORING AND ASSESSMENT OF CONCRETE STRUCTURES USING ACOUSTIC EMISSION
}

\author{
Ahmed A. Abouhussien ${ }^{1}$ and Assem A. A. Hassan ${ }^{2}$ \\ ${ }^{1}$ Department of Civil Engineering, Faculty of Engineering and Applied Science, \\ Memorial University of Newfoundland, St. John's, Newfoundland A1B 3X5, \\ Canada. \\ E-mail: aabouhussien@mun.ca \\ ${ }^{2}$ Department of Civil Engineering, Faculty of Engineering and Applied Science, \\ Memorial University of Newfoundland, St. John's, Newfoundland A1B 3X5, \\ Canada. \\ E-mail: ahassan@mun.ca
}

\begin{abstract}
This paper aims to employ acoustic emission (AE) technique to detect and identify the level of damage resulting from reinforcing steel corrosion in reinforced concrete structures. Five reinforced concrete prism samples with a constant concrete cover $(20 \mathrm{~mm})$ were subjected to an accelerated corrosion test. The samples were corroded until reaching five different levels of theoretical mass loss: 1, 2, 3, 4 and 5\% calculated using Faraday's law. The corrosion activity of the five samples was continuously monitored using attached AE sensors and a data acquisition system. The acquired AE signal parameters including AE signal strength, counts, energy, and number of hits were analyzed firstly to detect corrosion onset and secondly to predict the extent of damage as a result of corrosion propagation. The results obtained from AE monitoring were analyzed, evaluated, and compared to half-cell potential (HCP) measurements, and the amount of current passing with time. The analysis of these results involved comparing the AE cumulative signal strength (CSS) and each of the actual/theoretical percentages of mass loss, passed electrical current, and HCP readings. This analysis showed that CSS can be correlated to both HCP and electrical current at all degrees of damage from corrosion initiation up to $5 \%$ of mass loss. In addition, other AE signal parameters including number of hits, counts, and energy showed a significant increase in their cumulative values as the level of the theoretical mass loss, actual mass loss, and crack widths were increased. The results of this investigation confirmed that AE parameters (especially CSS) can be evaluated to detect corrosion earlier than other available nondestructive testing and evaluation techniques. Furthermore, it can be employed to represent the extent of damage occurring in reinforced concrete structures caused by corrosion of reinforcing steel.
\end{abstract}

Keywords: Acoustic emission, corrosion monitoring, nondestructive testing and evaluation, reinforced concrete structures.

\section{Introduction}

Bridges, tunnels, dams, parking garages, oil platforms and other forms of infrastructure are mostly made of reinforced concrete (RC). RC infrastructures exposed to extreme environments are deteriorating at an alarming rate due to concrete durability problems. As a result, periodical monitoring is required to detect any deterioration during the structure service lifetime to prevent any catastrophic failures. The corrosion of embedded reinforcing steel is the most critical factor 
for this deterioration (Gjørv 2002). Concrete is naturally alkaline, which is significant because the alkaline environment of concrete provides embedded steel with corrosion protection. Unfortunately, chlorides from deicing salts, groundwater, or seawater reduce the concrete alkalinity after penetrating the concrete cover and reaching the reinforcing steel. Corrosion starts once the percentage of the chloride around the steel bar exceeds the threshold needed for corrosion initiation. After initiation, corrosion propagates through the steel bars, eventually leading to concrete cover cracking, mass loss in the reinforcing bars, and ultimately, delimitation of the concrete cover (Hooton et al. 2002). Eventually, the overall strength of the structure decreases and may cause the structure to collapse if the required rehabilitation is not promptly implemented.

Structural Health Monitoring (SHM) is a non-destructive evaluation of structures that employs sensing technology to record, analyze, localize, and predict the loading, cracking, and damage of the monitored structure. SHM eliminates the need for routine site visits for evaluation and inspection of major civil structures and gives a warning of any potential damage. SHM system comprises of embedded or attached sensors, a data acquisition or signal processing system, and other electronics that periodically obtain data from the structure. These sensors provide quantitative data about the overall health of structures including: strains, deformations, temperature, moisture, and cracks. Examples of monitored structures are bridges, tunnels, dams, ships, platforms and pipelines (Mufti et al. 2007).

Acoustic Emission (AE) technique is defined as a passive SHM method with the ability of detecting any possible damage in civil structures. AE sensors are sensitive to the micro-cracking stage of damage which is considered insignificant from the structural point of view (Nair and Cai 2010). Micro-cracks resulting from any source of damage in structures eventually cause releasing strain energy, thus initiating elastic waves that can be collected by AE sensors (Ziehl 2008; Pollock 1986). It should be noted that, special data filtering to exclude unwanted noise should be implemented to obtain valuable information from the obtained AE signals. AE sensors can measure a variety of signal parameters when attached to the structure's surface or embedded inside. AE sensors can be used in SHM system to detect any signal emitted from any form of stresses happening in a structure (Ohtsu et al 2002).

The use of AE technology has recently been extended to monitor corrosion in reinforced concrete structures (Ohtsu and Tomoda 2008). Benedetti et al. (2013) tested the feasibility of using attached $\mathrm{AE}$ sensors to detect corrosion initiation in small-scale samples. The outcomes from their experimental study show that the AE signal parameters can be analyzed to give an indication of corrosion inception. More recently, SHM has been employed to identify the onset and growth of cracks due to corrosion of reinforcing steel in concrete (ElBatanouny et al. 2014). Owing to the limited research of the $\mathrm{AE}$ technique, further research is needed to optimize the application of $\mathrm{AE}$ sensors for corrosion monitoring and damage assessment considering the effects of crack widths created by expansions of reinforcing steel as corrosion progresses. The objective of this study is to apply the $\mathrm{AE}$ technique to evaluate the extent of damage in reinforced concrete under corrosion attack. The acquired signals were analyzed to evaluate the level of damage that follows corrosion of steel in reinforced concrete as a function of different AE signal parameters.

\section{Acoustic Emission Analysis}

\subsection{Definitions of AE Signal Parameters}

Different AE signal parameters have been considered for damage analysis in concrete structures. These parameters include signal strength, absolute energy, amplitude, rise time, duration, counts, and hits, as shown in Figure 1. Complete definitions of different AE parameters used in nondestructive testing industry can be found elsewhere (ASTM 2014). Each parameter (or a combination of parameters) can be assessed to identify and evaluate the level of damage 
occurring at the source of the recorded signal. The type of the parameters to be monitored depends on the method of AE data analysis based on the type of application.

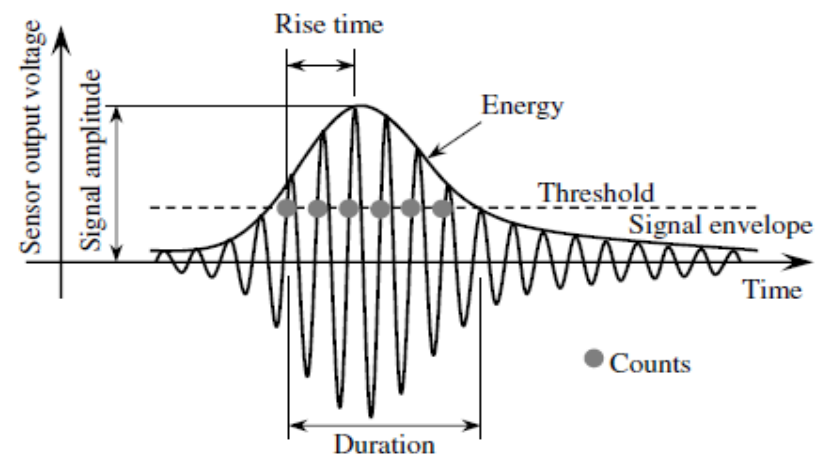

Figure 1. Typical AE signal parameters (Mistras Group 2007).

\subsection{Methodology of Acoustic Emission Analysis}

Different researchers employed the raw AE signal parameters collected from continuous SHM to detect, quantify, and localize variable types of structural damage. For instance, the average frequency (count/time) and RA value (rise time/maximum amplitude) were applied to classify different forms of cracks in concrete structures (Ohtsu 2010). This analysis showed the ability to differentiate between tensile or shear cracks resulted from external loads on structures. On the other hand, corrosion detection in prestressed concrete structures was achieved by analyzing the history of cumulative signal strength (CSS) in accelerated corrosion test (ElBatanouny et al. 2014). Alternatively, cumulative number of hits can be exploited to identify corrosion activity (Li et al. 1998, Ohtsu and Tomoda 2008). Further research was conducted to quantify damage in concrete structures using AE data was by performing an intensity analysis (Mangual et al. 2013) which was first applied in in fiber-reinforced polymer (FRP) vessels (Fowler et al 1989). In this analysis, two parameters (historic index and severity) are calculated based on signal strength values and are employed to assess the level of damage occurring in structures. This analysis was further employed for the assessment of damage in presterssed concrete beams subjected to cyclic loading and to corrosion of prestressing strands (Abdelrahman et al. 2014, ElBatanouny et al. 2014). Eventually, their results were utilized to develop intensity classification charts to evaluate corrosion levels and measure the reduction in capacity of prestressed concrete elements. However, more research was suggested to validate and confirm the classification areas of these intensity classification charts.

\section{Experimental Program}

In this study, the AE technique was applied to monitor the rate of corrosion in five small-scale prism reinforced concrete samples. These samples were casted with constant concrete cover around the embedded steel bar $(20 \mathrm{~mm})$. The samples were then subjected to a curing period of 28 days prior to testing. After the curing period, the samples were subjected to an accelerated corrosion test to reach different levels of damage. The degree of damage was evaluated based on the theoretical mass loss of the reinforcing steel bar predicted using Faraday's law. Five variable degrees of damage were obtained including 1, 2, 3, 4, and 5\% theoretical mass loss. The samples were connected to a DC power supply to serve as anodes $(+)$, while a steel mesh was positioned under the samples to serve as a cathode (-). The samples were exposed to a constant volt (12 Volts) throughout the whole experiment. The five samples were partially submerged in a $5 \% \mathrm{NaCl}$ solution in a container as seen in Figure 2. Two AE sensors were attached to each prism sample on 
the top of the steel bar. The sensors were attached to the specimen top by means of an epoxy adhesive. The reinforcing steel corrosion rate was continuously monitored for the five samples using a 4-channel AE data acquisition system and an AEwin signal processing software (Mistras Group 2007). The values of the passed electric current for each sample were continuously recorded at one-minute intervals using a computer-controlled data-acquisition system. In addition, the half-cell potential (HCP) difference between the embedded steel bar and a reference electrode was measured according to ASTM C876 (ASTM 1991) on a daily basis. The theoretical percentage of mass loss was estimated using Faraday's law based on the values of passed electric current (Hassan et al. 2009). Upon reaching the presumed values of mass loss (1 to 5\%), the sample was removed from the test and the final AE signal parameters and half-cell potentials were recorded. The actual percentage of the mass loss of all samples was measured at the end of the test for comparison as specified on ASTM G1 (ASTM 2014).

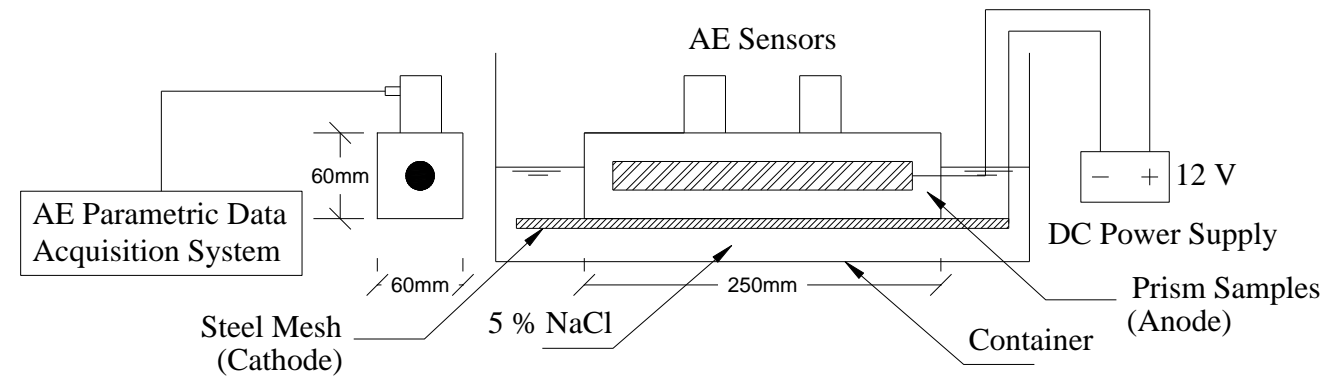

Figure 2. Accelerated corrosion and AE monitoring test set-up.

\subsection{Materials and Mixture Properties}

In this study, type GU Canadian Portland cement similar to ASTM Type I, with a specific gravity of 3.15, was used for the concrete mixture. Natural sand and $10 \mathrm{~mm}$ maximum size stone were included as fine and coarse aggregates, respectively. The coarse and fine aggregates each had a specific gravity of 2.60 and water absorption of $1 \%$. Reinforcing steel bars with a $20 \mathrm{~mm}$ diameter were used in each of the five prism samples. A high range water reducer admixture (HRWRA), similar to ASTM Type F (ASTM 2013), was applied to attain the required workability of the concrete mixture. The mixture proportions and compressive strength are shown in Table 1.

Table 1. Mixture proportions and compressive strength for the concrete mixture.

\begin{tabular}{|c|c|c|c|c|c|}
\hline $\begin{array}{c}\text { Cement } \\
\left(\mathrm{kg} / \mathrm{m}^{3}\right)\end{array}$ & $\begin{array}{c}10 \mathrm{~mm} \text { Stone } \\
\left(\mathrm{kg} / \mathrm{m}^{3}\right)\end{array}$ & $\begin{array}{c}\text { Sand } \\
\left(\mathrm{kg} / \mathrm{m}^{3}\right)\end{array}$ & $\begin{array}{c}\text { Water } \\
\left(\mathrm{kg} / \mathrm{m}^{3}\right)\end{array}$ & $\begin{array}{c}\text { HRWRA } \\
\left(\mathrm{L} / \mathrm{m}^{3}\right)\end{array}$ & $\begin{array}{c}28-D a y s \\
(\mathrm{MPa})\end{array}$ \\
\hline 350 & 1168.27 & 778.84 & 140 & 1.875 & 33.47 \\
\hline
\end{tabular}

\subsection{Acoustic Emission Measurement Setup}

The setup of parameters in the data acquisition system is significant for selecting the important signal parameters for continuous monitoring prior to test. In addition, the data filters should be predefined to screen the data and discard any unwanted signals or noise (ElBatanouny et al. 2014). Table 2 shows the parameters which were entered in the data acquisition software as recommended by the manufacturer (Mistras Group 2007). AE sensors having $40 \mathrm{~dB}$ integral preamplification (R6I) were mounted on each specimen (Mistras Group 2005). In this study, cumulative signal strength was analyzed for detecting both the onset and progression of the corrosion in all tested samples. Similar approach was successfully employed for corrosion monitoring in presteressed concrete structures (Mangual et al. 2013; ElBatanouny et al. 2014) 
Table 2. Data acquisition hardware setting.

\begin{tabular}{|c|c|c|c|c|c|c|c|c|c|}
\hline \multirow{2}{*}{$\begin{array}{l}\text { Thresho } \\
\text { (dB) }\end{array}$} & \multicolumn{2}{|c|}{ Analog Filter $(\mathrm{kHz}$} & \multicolumn{3}{|c|}{ Wave Form Setup } & \multicolumn{4}{|c|}{ Timing Parameters } \\
\hline & Lower & Upper & $\begin{array}{c}\text { Sampling } \\
\text { Rate } \\
\text { (MSPS) }\end{array}$ & $\begin{array}{c}\text { Pretrigge } \\
(\mu \mathrm{s})\end{array}$ & $\begin{array}{r}\text { Length } \\
\text { (points) }\end{array}$ & $\begin{array}{r}\text { PDT } \\
(\mu \mathrm{s})\end{array}$ & $\begin{array}{r}\text { HDT } \\
(\mu \mathrm{s})\end{array}$ & $\begin{array}{r}\mathrm{HLT} \\
(\mu \mathrm{s})\end{array}$ & $\begin{array}{c}\text { Maximum } \\
\text { Duration } \\
(\mu s)\end{array}$ \\
\hline 40 & 1 & 1000 & 5 & 256 & $2 \mathrm{k}$ & 200 & 800 & 1000 & 1000 \\
\hline
\end{tabular}

\section{Discussion of Test Results}

Table 3 shows a summary of the results obtained at the end of the accelerated corrosion experiments. In addition, the data collected by the two AE sensors in each sample were averaged and are also described in Table 3. The results from $\mathrm{AE}$ data acquisition are cumulative $\mathrm{AE}$ parameters calculated for each sample at the end of the accelerated corrosion testing period.

Table 3. Summary of experimental results at the end of the accelerated corrosion test.

\begin{tabular}{|c|c|c|c|c|c|c|c|c|c|c|}
\hline $\begin{array}{c}\text { Specime } \\
\mathrm{n}\end{array}$ & $\begin{array}{c}\text { Test } \\
\text { Duration } \\
\text { (hours) }\end{array}$ & $\begin{array}{c}\text { Averag } \\
\mathrm{e} \\
\text { Anodic } \\
\text { Current } \\
(\mathrm{mA})\end{array}$ & $\begin{array}{c}\text { Theoretical } \\
\text { Mass Loss } \\
\text { of Steel (\%) }\end{array}$ & $\begin{array}{c}\text { Actual } \\
\text { Mass } \\
\text { Loss of } \\
\text { Steel }(\%)\end{array}$ & $\begin{array}{c}\text { HCP } \\
(\mathrm{mV})\end{array}$ & $\begin{array}{l}\text { Crack } \\
\text { Width } \\
(\mathrm{mm})\end{array}$ & \multicolumn{3}{|c|}{ Cumulative AE Parameters } \\
\hline $20-1$ & 72 & 66 & 1 & 0.8 & -355 & 0.10 & 228.5 & 741.3 & 179.5 & 0.9 \\
\hline $20-2$ & 120 & 78 & 2 & 1.4 & -385 & 0.65 & 245.6 & 803.8 & 199.7 & 4.8 \\
\hline $20-3$ & 144 & 99 & 3 & 2.2 & -423 & 0.80 & 246.7 & 804.2 & 202.7 & 5.2 \\
\hline $20-4$ & 168 & 110 & 4 & 3.5 & -448 & 2.20 & 249.8 & 809.9 & 205.9 & 5.5 \\
\hline $20-5$ & 240 & 117 & 5 & 3.7 & -590 & 5.00 & 256.2 & 815.4 & 207.5 & 7.0 \\
\hline
\end{tabular}

\subsection{Corrosion Detection Using AE Technique}

The results of CCS samples 20-5 (as an example) are shown in Figure 3 versus the values of HCP readings. It can be seen that an overall increase in the CSS was recorded as a result of both corrosion initiation and propagation which was accompanied with the cover cracking. The CSS curve has two clear jumps (significant increase in a relatively short period) in values which indicated both corrosion initiation and cracking onset. The first jump was detected at nearly 40 hours which can be explained by the formation of micro-cracks following steel de-passivation due to corrosion. It can also be noticed from that the HCP value at the same point was more positive than -250 which indicates that no active corrosion was detected by the HCP test. This result reflects the higher sensitivity of the AE technique than the traditional HCP test which detected corrosion at a later stage (approximately 60 hours). By further reviewing the CSS values it is obvious that another significant increase was occurred after 60 hours of the test. This second increase was attributed to the onset of first visual crack of $0.1 \mathrm{~mm}$ which was followed by successive increase in the crack width and corrosion activity. Nonetheless, the CSS values kept increasing throughout the test owing to the continuous opening of crack width from 0.1 to $5 \mathrm{~mm}$. These results confirm the capability of AE sensors to detect both corrosion initiation and propagation which matched the results obtained from other similar research works (Ohtsu and Tomoda 2008, ElBatanouny et al. 2014). It is worth noting that the other tested samples $(20-1,20-$ 2, 20-3, and 20-4) showed similar trends of CSS versus test times and were also successfully used for detecting corrosion inception earlier than HCP test. These samples took approximately between 20 to 40 hours in the accelerated corrosion for corrosion initiation to be detected similarly using CSS analysis. 


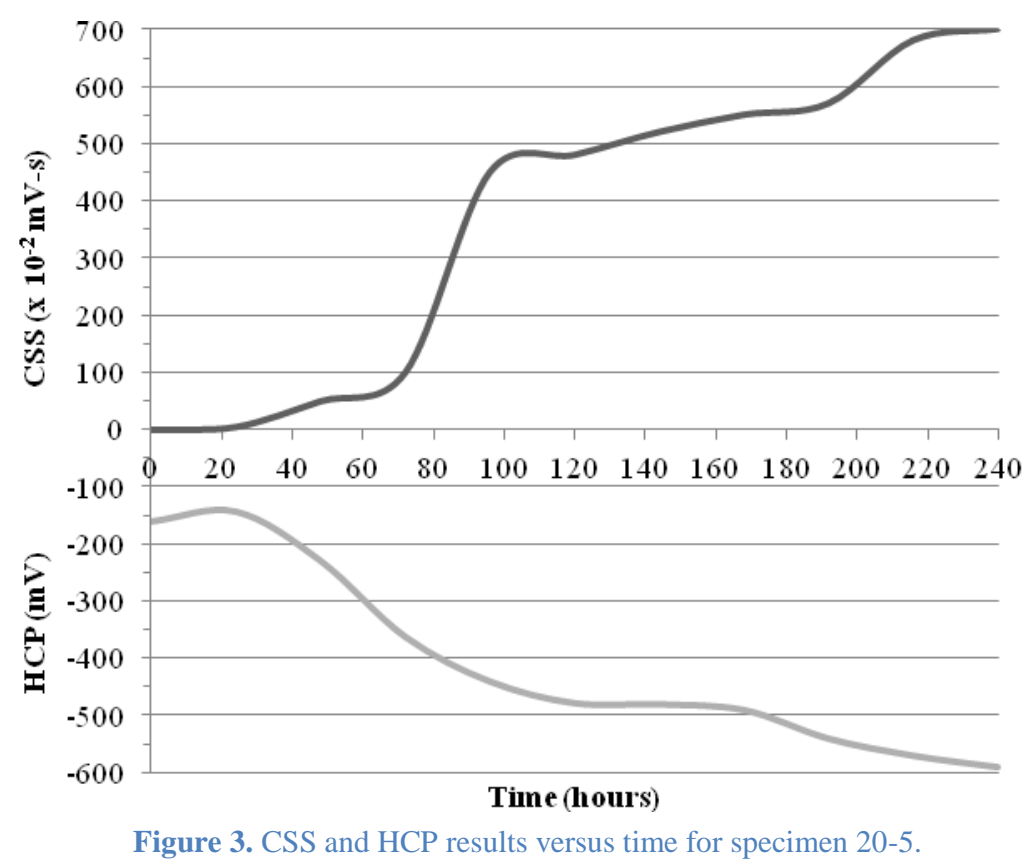

\subsection{Damage Evaluation Using AE Technique}

The results of the recorded AE events are presented in Table 3 for the five tested samples at the end of each test. These samples were corroded for different periods (72-240 hours) to reach five different levels of theoretical mass loss of steel $(1-5 \%)$ and yielded five actual degrees of mass loss (0.8-3.7\%). This increase in corrosion rate resulted in increasing the cover crack width $(0.1-$ $5 \mathrm{~mm}$ ) owing to the expansion of steel and accumulation of corrosion products. It should be noted that all samples showed one longitudinal cover crack approximately at the center of the embedded steel bar. These five different levels of corrosion damage were identified by the commutative AE parameters measured at the end of tests. For instance, the recorded CSS was linearly increased (from $0.9 \mathrm{mV}$-s in sample 20-1 to $7 \mathrm{mV}$-s in sample 20-5) due to the increase in corrosion rate in theses samples (see Table 3). Moreover, the other collected AE parameters including the number of $\mathrm{AE}$ hits, counts, and energy showed similar increase because of corrosion development from sample 20-1 through 20-5. It can be concluded that the AE results can be correlated to the degree of damage caused by corrosion of steel in concrete. These trends were also confirmed from both the increased HCP results from -355 to -590 and the passed electrical current measured for the five tested samples. This comparison indicated the effectiveness of AE monitoring as a novel SHM system for damage assessment of concrete structures subjected to reinforcing steel corrosion. However, additional tests are necessary to develop more valuable relationships between $\mathrm{AE}$ parameters and the extent of damage in concrete structures.

\section{Conclusions}

In this paper, $\mathrm{AE}$ sensors were employed to continuously monitor the progression of corrosion of steel in concrete samples. Five RC samples were subjected to accelerated corrosion test to obtain five different levels of mass loss. Meanwhile, the AE signals resulted from corrosion of steel were constantly recorded using a data acquisition system. AE results were compared to those obtained from HCP test, mass loss, crack widths, and electrical currents. The following conclusions are drawn from the analysis of both the AE data and experimental results simultaneously: 
1- AE technique showed a superior performance in detecting corrosion initiation earlier than HCP test owing to its high sensitivity to micro-damage accompanying corrosion of steel. This was performed by reviewing the history of CSS of the collected samples throughout the tests.

2- CSS analysis may be utilized for both detecting the corrosion initiation and estimating the degree of corrosion when compared and correlated with the corresponding values of mass loss and crack widths resulting from corrosion of reinforcing steel.

3- All recorded AE parameters including number of hits, counts, and energy showed a clear correlation when compared to HCP test results and visual observations for all tested samples.

4- The presence of surface cracks has a significant effect on both the corrosion propagation process and recorded AE hits. Thus, the analysis of AE data from corrosion testing should be performed while considering the cracking behavior (number and width of cracks).

5- SHM using AE sensors can continuously give useful information regarding the corrosion activity, which can indicate the remaining capacity of concrete structures.

\section{References}

Abdelrahman, M., ElBatanouny, M. K. and Ziehl, P. H. (2014). Acoustic emission based damage assessment method for prestressed concrete structures: Modified index of damage, Engineering Structures, 60: 258-264.

ASTM C876 (1991). Standard test method for half-cell potentials of uncoated reinforcing steel in concrete, ASTM International, West Conshohocken, PA, USA.

ASTM C494 (2013). Standard specification for chemical admixtures for concrete," in Annual Book of ASTM Standards, ASTM International, West Conshohocken, PA, USA.

ASTM E1316 (2014). Standard terminology for nondestructive examinations, ASTM International, West Conshohocken, PA, USA.

ASTM G1 (2011). Standard practice for preparing, cleaning, and evaluating corrosion test specimens, ASTM International, West Conshohocken, PA, USA.

ElBatanouny, M., Mangual, J., Ziehl, P., and Matta, F. (2014). Early corrosion detection in prestressed concrete girders using acoustic emission, Journal of Materials in Civil Engineering, 26: 504-511.

Fowler, T., Blessing, J., and Conlisk, P. (1989). New directions in testing, In Proceedings, Int. Conf. of Acoustic Emission from Composite Materials, K. Ono, ed., Acoustic Emission Working Group, Memphis, TN, 16-27.

Gjørv, O. E. (2002). Durability and service life of concrete structures, In Proceedings 6, The First fib Congress of Japan Prestressed Concrete Engineering Association, Tokyo, Japan, 1-16.

Hassan, A. A. A., Hossain, K. M. A., Lachemi, M. (2009). Corrosion resistance of selfconsolidating concrete in full-scale reinforced beams, Cement \& Concrete Composites, 31: 29-38.

Hooton, R. D., Geiker, M. R., and Bentz, E. C. (2002). Effects of curing on chloride ingress and implications on service life, ACI Materials Journal, 99: 201-206.

Li, Z., Zdunek, A., Landis, E., and Shah, S. (1998). Application of acoustic emission technique to detection of reinforcing steel corrosion in concrete, ACI Materials Journal, 95(1): 68-76.

Mangual, J., ElBatanouny, M., Ziehl, P., and Matta, F. (2013). Corrosion damage quantification of prestressing strands using acoustic emission, Journal of Materials in Civil Engineering, 25(9): 1326- 1334.

Mistras Group (2005). R6I-AST sensor, Physical Acoustics Corporation, Princeton Junction, NJ, USA.

Mistras Group (2007). PCI-2 Based AE System User's Manual. Physical Acoustics Corporation, Princeton Junction, NJ, USA. 
Mufti, A. A., Bakht, B., Tadros, G., Horosko, A. T., and Sparks, G. (2007). Civionics - A new paradigm in design, evaluation, and risk analysis of civil structures, Journal of Intelligent Material Systems and Structures, 18: 757-763.

Nair, A., and Cai, C. S. (2010). Acoustic emission monitoring of bridges: Review and case studies, Engineering Structures, 32(6), 1704-1714.

Ohtsu, M., Uchida, M., Okamoto, T., and Yuyama, S. (2002). Damage assessment of reinforced concrete beams qualified by acoustic emission, ACI Structural Journal, 99(4): 411-417.

Ohtsu, M., and Tomoda, Y., (2008). Phenomenological model of corrosion process in reinforced concrete identified by acoustic emission, ACI Materials Journal, 105(2): 194-199.

Ohtsu, M. (2010). Test method for classification of active cracks in concrete structures by acoustic emission, Materials and Structures, 43:1187-1189.

Pollock, A. A. (1986). Classical wave theory in practical AE testing, In Proceedings, Int. Acoustic Emission Symp., Japanese Society for Nondestructive Testing, 708-721.

Yoon, D., Weiss, W., and Shah, S. (2000) Assessing Damage in Corroded Reinforced Concrete Using Acoustic Emission, Journal of Engineering Mechanics, 126(3): 273-283.

Ziehl, P. (2008). Applications of acoustic emission evaluation for civil infrastructure, In Proceedings, Smart Structures and Materials, Nondestructive Evaluation and Health Monitoring, Society of Photo-Optical Instrumentation Engineers, Bellingham, WA, 693401. 